\title{
ON A GENERALIZATION OF CLOSE-TO-CONVEXITY
}

\author{
K. INAYAT NOOR \\ Mathematics Department \\ Science College of Education for Girls \\ Sitteen Road, Riyddh, Saudi Arabia \\ (Received July 9, 1979 and in revised form August 30, 1982)
}

ABSTRACT. A class $T_{k}$ of analytic functions in the unit disc is defined in which the concept of close-to-convexity is generalized. A necessary condition for a function $f$ to belong to $\mathrm{T}_{k}$, raduis of convexity problem and a coefficient result are solved in this paper.

KEY WORDS AND PHRASES. ClOse-to-convex functions, functions of bounded boundary rotation, necessary condition, radius of convexity, generalized Koebe function.

1980 MATHEMATICS SLBJECT CLASSIFICATION CODES. Primary 30A32, secondary $30 A 34$.

1. INTRODUCTION.

This paper is directed to mathematical specialists or non-specialists familiar with multivalent functions [1], and to close-to-convex functions [2].

Let $V_{k}$ be the class of functions of bounded boundary rotation and $\mathrm{K}$ be the class of close-to-convex functions. We generalize the concept of close-to-convexity in the following direction.

Definition. Let $f$ with $f(z)=c z+\sum_{n=2}^{\infty} a_{n} z^{n}$ be analytic in $E=\{z:|z|<1\},|c|=1$ and $f^{\prime}(z) \neq 0$. Then $f \varepsilon T_{k}, k \geq 2$, if there exist a function $g \varepsilon V_{k}$ such that, for $z \varepsilon E$

$$
\operatorname{Re} \frac{f^{\prime}(z)}{g^{\prime}(z)}>0
$$

It is clear that $\mathrm{T}_{2} \equiv \mathrm{K}$.

Using a method by Kaplan [2], we have

THEOREM 1. Let $\mathrm{f} \varepsilon \mathrm{T}_{\mathrm{k}}$. Then with $z=r e^{i \theta}$ and $\theta_{1}<\theta_{2}$

$$
\int_{\theta}^{\theta} \operatorname{Re}_{1}^{2}\left\{\frac{\left(z f^{\prime}(z)\right)^{\prime}}{f^{\prime}(z)}\right\} d \theta>-\frac{k}{2}
$$


REMARK 1. From theorem 1, we can interpret some geometric meaning for the class $\mathrm{T}_{\mathbf{k}}$. For simplicity, let us suppose that the image domain is bounded by an analytic curve C. At a point on $C$, the outward drawn normal has an angle $\arg \left[e^{i \theta} f^{\prime}\left(e^{i \theta}\right)\right]$. Then from (1.2), it follows that the angle of the outward drawn normal turns back at most $\frac{k}{2} \pi$ This is a necessary condition for a function $f$ to belong to $T_{k}$. It will be interesting to see if this condition is also sufficient.

REMARK 2. Goodman [3] defines the class $K(\beta)$ of functions as follows.

Let $f$ with $f(z)=z+\sum_{n=2}^{\infty} a_{n} z^{n}$ be analytic in $E$ and $f^{\prime}(z) \neq 0$. Then for $\beta>0, f \varepsilon K(\beta)$, if for $z=r e^{i \theta}$ and $\theta_{1}<\theta_{2}$

$$
\int_{\theta}^{\theta} \operatorname{Re}\left[\frac{\left(z f^{\prime}(z)\right)^{\prime}}{f^{\prime}(z)}\right] d \theta>-\beta \pi
$$

We note that $\mathrm{T}_{\mathrm{k}} \subset \mathrm{k}\left(\frac{\mathrm{k}}{2}\right)$.

2. MAIN RESULTS

From remark 2 and results given in [3] for the class $K(\beta)$, we have at once THEOREM 2. Let $\mathrm{f} \varepsilon \mathrm{T}_{\mathrm{k}}$.

(i) Denote by $L(r, f)$ the length fo the image of the circle $|z|=r$ under $f$ and by $A(r, f)$ the area of $f(|z|=r)$. Then for $0 \leq r<1$,

$$
\begin{aligned}
& \text { (a) } \mathrm{L}(\mathrm{r}, \mathrm{f}) \leq \mathrm{L}\left(\mathrm{r}, \mathrm{F}_{\mathrm{k}}\right) \text {, } \\
& \text { (b) } A(r, f) \leq A\left(r, F_{k}\right) \text {, }
\end{aligned}
$$

where $F_{k}$ is defined by, for $z \in E$,

$$
\begin{aligned}
F_{k}(z) & =\frac{1}{(k+2)}\left[\left(\frac{1+k}{1-z}\right)^{\frac{1}{2} k+1}-1\right] \\
& =z+\sum_{n=2}^{\infty} A_{n}(k) z^{n}
\end{aligned}
$$

and clearly $\mathrm{F}_{\mathrm{k}} \in \mathrm{T}_{\mathrm{k}}$.

$$
\left|a_{n}\right| \leq A_{n}(k), n=2,3, \ldots \ldots \ldots, k \geq 2
$$

where $A_{n}(k)$ is defined by (2.1). This result is sharp for each $n \geq 2$.

(iii) For $z=r \mathrm{e}^{i \theta}, 0 \leq r<1$,

$$
\frac{(1-r)^{\frac{1}{2} k}}{(1+r)^{\frac{1}{2} k+2}} \leq\left|f^{\prime}(z)\right| \leq \frac{(1+r)^{\frac{1}{2} k}}{(1-r)^{\frac{1}{2} k+2}}
$$

These bounds are sharp, equality being attained for the function $F_{k}$ defined by (2.1). 
We also need the following result.

Lemma 1 [4]. Let $g \varepsilon V_{k}$. Then there are two starlike functions $s_{1}$ and $s_{2}$ such that for $z \varepsilon E$

$$
g^{\prime}(z)=\frac{\left(s_{1}(z) / z\right)^{\frac{1}{4} k+\frac{1}{2}}}{\left(s_{2}(z) / z\right)^{\frac{1}{4} k-\frac{1}{2}}}
$$

THEOREM 3. $\mathrm{f}_{\varepsilon \mathrm{T}_{\mathrm{k}}}$ if and only if

$$
f^{\prime}(z)=\frac{\left(k_{1}^{\prime}(z)\right)^{\frac{1}{4} k+\frac{1}{2}}}{\left(k_{2}^{\prime}(z)\right)^{\frac{1}{4} k-\frac{1}{2}}}, \quad k_{1}, k_{2} \varepsilon k
$$

PROOF: From definition 1, we have

$$
f^{\prime}(z)=g^{\prime}(z) h(z), \quad g \in V_{k} \text { and } \operatorname{Re} h(z)>0 .
$$

Using lemma 1 , we know that there are two starlike functions $s_{1}$ and $s_{2}$ such that $z \varepsilon E$,

$$
g^{\prime}(z)=\frac{\left(s_{1}(z) / z\right)^{\frac{1}{4} k+\frac{1}{2}}}{\left(s_{2}(z) / z\right)^{\frac{1}{4} k-\frac{1}{2}}}
$$

Thus

$$
\begin{aligned}
f^{\prime}(z)= & \frac{\left(s_{1}(z) / z\right)^{\frac{1}{4} k+\frac{1}{2}}}{\left(s_{2}(z) / z\right)^{\frac{1}{4} k-\frac{1}{2}}} h(z)=\frac{\left(\left(s_{1}(z) h(z)\right) / z\right)^{\frac{1}{4} k+\frac{1}{2}}}{\left(\left(s_{2}(z) h(z)\right) / z\right)^{\frac{1}{4} k-\frac{1}{2}}} \\
= & \frac{\left(k_{1}^{\prime}(z)\right)^{\frac{1}{4} k+\frac{1}{2}}}{\left(k_{2}^{\prime}(z)\right)^{\frac{1}{4} k-\frac{1}{2}}}
\end{aligned}
$$

where $k_{1}$ and $k_{2}$ are two suitable selected close-to-convex functions.

Lemma 2. Let $\mathrm{H}$ be analytic and be defined as

$$
\begin{aligned}
& H(z) g^{\prime}(z)=\left(z g^{\prime}(z)\right)^{\prime}, g \varepsilon V_{k} \text { and } H(z)=\left(\frac{k}{4}+\frac{1}{2}\right) h_{1}(z)-\left(\frac{k}{4}-\frac{1}{2}\right) h_{2}(z), \\
& \operatorname{Re} h_{i}(z)>0, i=1,2, h_{i}(0)=1
\end{aligned}
$$

Then

$$
\frac{1}{2 \pi} \int_{0}^{2 \pi}|H(z)|^{2} \mathrm{~d} \theta \leq \frac{1+\left(k^{2}-1\right) r^{2}}{1-r^{2}} \quad\left(z=r e^{i \theta}\right)
$$

and

$$
\frac{1}{2 \pi} \int_{0}^{2 \pi}\left|H^{\prime}(z)\right| d \theta \leq \frac{k}{1-r^{2}}
$$

PROOF: By the representation formula due to Paatero [5], we can write 
where

$$
H(z)=\frac{1}{2 \pi} \int_{0}^{2 \pi} \frac{1+z e^{i t}}{1-z e^{i t}} d \mu(t)
$$

$$
\int_{0}^{2 \pi} d \mu(t)=2 \pi, \text { and } \quad \int_{0}^{2 \pi}|d \mu(t)| \leq k \pi
$$

Let $H(z)=1+\sum_{n=1}^{\infty} c_{n} z^{n}$

Then

$$
\begin{aligned}
& c_{n}=\frac{1}{\pi} \int_{0}^{2 \pi} e^{-i n t} d \mu(t), \text { and so for } n \geq 1 \\
& \left|c_{n}\right| \leq \frac{1}{\pi} \int_{0}^{2 \pi}|d \mu(t)| \leq k
\end{aligned}
$$

Thus

$$
\frac{1}{2 \pi} \int_{0}^{2 \pi}|H(z)|^{2} \mathrm{~d} \theta=\sum_{n=0}^{\infty}\left|c_{n}\right|^{2} r^{2 n} \leq\left(1+k^{2} \sum_{n=1}^{\infty} r^{2 n}\right)=\frac{1+\left(k^{2}-1\right) r^{2}}{1-r^{2}}
$$

Also

$$
H^{\prime}(z)=\frac{1}{\pi} \int_{f\left(1-z e^{i t}\right)^{2}}^{2 \pi} d \mu(t)
$$

Thus

$$
\frac{1}{2 \pi} \int_{0}^{2 \pi}\left|H^{\prime}(z)\right| d \theta \leq \frac{1}{\pi} \int_{0}^{2 \pi} \frac{1}{2 \pi} \int_{0}^{2 \pi} \frac{1}{\left|1-e^{i(\theta+t)}\right|^{2}} d \theta|d \mu(t)| \leq \frac{1}{1-r^{2}} \frac{1}{\pi} \int_{0}^{2 \pi}|d \mu(t)| \leq \frac{k}{1-r^{2}}
$$

THEOREI1 4: Let $f \varepsilon \mathrm{T}_{\mathrm{k}} \cdot$ Then for $\mathrm{n} \geq 1$,

$$
|| a_{n+1}|-| a_{n}|| \leq c(k) n^{\frac{k}{2}-1} \text {, }
$$

where $c(k)$ is a constant and depends only on $k$.

PROOF: Since $f \varepsilon T_{k}$, we have for $z \varepsilon E$,

$$
f^{\prime}(z)=g^{\prime}(z) h(z), \quad g \varepsilon V_{k} \quad \text { and } \operatorname{Re} h(z)>0
$$

Set

$$
F(z)=z\left(z f^{\prime}(z)\right)^{\prime}=z g^{\prime}(z)\left[H(z) h(z)+z h^{\prime}(z)\right],
$$

where $\operatorname{Re} h(z)>0$ and $H(z) g^{\prime}(z)=\left(z g^{\prime}(z)\right)^{\prime}$, with

$$
H(z)=\left(\frac{k}{4}+\frac{1}{2}\right) h_{1}(z)-\left(\frac{k}{4}-\frac{1}{2}\right) h_{2}(z), \quad \operatorname{Re} h_{i}(z)>0, i=1,2, h_{i}(0)=1
$$

Thus, for $\xi \in \mathrm{E}$ and $\mathrm{n} \geq 1$; 


$$
\left|(n+1)^{2} \xi a_{n+1}-n^{2} a_{n}\right| \leq \frac{1}{2 \pi r^{n+1}} \int_{0}^{2 \pi}|z-\xi||F(z)| d \theta,
$$

and by using lemma 1 and (2.2), we obtain

$$
\left|(n+1){ }^{2} \xi a_{n+1}-n^{2} a_{n}\right| \leq \frac{1}{2 \pi r^{n+1}} \int_{0}^{2 \pi}|z-\xi| \frac{\left|s_{1}(z)\right|^{\frac{1}{4} k+\frac{1}{2}}}{\left|s_{2}(z)\right|^{\frac{1}{4} k-\frac{1}{2}}}\left|H(z) h(z)+z h^{\prime}(z)\right| d \theta,
$$

where $s_{1}, s_{2}$ are starlike functions.

It is wel1-known [1] that for starlike function $s \varepsilon S$,

$$
\frac{r}{(1+r)^{2}} \leq|s(z)| \leq \frac{r}{(1-r)^{2}}
$$

Let $0<\mathbf{r}<1$. Then by a result of Golusin $[6, p 162]$, there exists a $z_{1}$ with $|z|=r$ such that for all $z,|z|=r$,

$$
\left|z-z_{1}\right|\left|s_{1}(z)\right| \leq \frac{2 r^{2}}{1-r^{2}} \text {. }
$$

From (2.3)-(2.5), we have

$$
\left|(n+1)^{2} \xi a_{n+1}-n^{2} a_{n}\right| \leq \frac{1}{2 \pi r^{n+1}}\left(\frac{4}{r}\right)^{\frac{1}{4} k-\frac{1}{2}}\left(\frac{2 r^{2}}{1-r^{2}}\right)\left(\frac{r}{(1-r)^{2}}\right)^{\frac{1}{4} k-\frac{1}{2}} \int^{2 \pi}\left|H(z) h(z)+z h^{\prime}(z)\right| d \theta
$$

Now as in [7], we have with $z=r e^{i \theta}$

$$
\frac{1}{2 \pi} \int_{0}^{2 \pi}|h(z)|^{2} d \theta \leq \frac{1+3 r^{2}}{1-r^{2}}
$$

and

$$
\frac{1}{2 \pi} \int_{0}^{2 \pi}\left|z h^{\prime}(z)\right| d \theta \leq \frac{2 r}{1-r^{2}}, \quad \text { where } \operatorname{Re} h(z)>0
$$

Also

$$
\begin{gathered}
\frac{1}{2 \pi} \int_{0}^{2 \pi}\left|H(z) h(z)+z h^{\prime}(z)\right| d \theta \leq \frac{1}{2 \pi} \int_{0}^{2 \pi}|H(z) h(z)| d \theta+\frac{1}{2 \pi} \int_{0}^{2 \pi}\left|z h^{\prime}(z)\right| d \theta \\
\leq \frac{\left(1+\left(k^{2}-1\right) r^{2}\right)^{\frac{1}{2}}\left(1+3 r^{2}\right)^{\frac{1}{2}}}{1-r^{2}}+\frac{2 r}{1-r^{2}}
\end{gathered}
$$

by using Schwarz's inequality, lemma 2 and (2.7).

Hence from (2.6) and (2.8), we have

$$
\left|(n+1)^{2} \xi a_{n+1}-n^{2} a_{n}\right| \leq \frac{1}{r^{n+1}} 2^{\frac{1}{2} k}\left[\left(1+\left(k^{2}-1\right) r^{2}\right)^{\frac{1}{2}}+1\right] \frac{1}{(1-r)^{\frac{1}{2} k+1}},
$$


and so choosing $|\xi|=r=\left(\frac{n}{n+1}\right)^{2}$, we obtain for $n \geq 1$

$$
n^{2}|| a_{n+1}|-| a_{n}|| \leq\left[\left(1+\left(k^{2}-1\right) r^{2}\right)^{\frac{1}{2}}+1\right] e^{2} 2^{\frac{1}{2} k+2}\left(\frac{4}{3}\right)^{\frac{1}{2} k+1} n^{\frac{1}{2} k+1}
$$

Thus

$$
|| a_{n+1}|-| a_{n}|| \leq c(k) n^{\frac{1}{2} k-1} \text {. }
$$

The function $F_{k}$ defined by (2.1) shows that the index $\left(\frac{k}{2}-1\right)$ is best possible.

We now evaluate the radius of convexity for the class $T_{k}$.

THEOREM 5: Let $\mathrm{f}_{\varepsilon \mathrm{T}_{k}}$. Then the radius $\mathrm{R}$ of the circle which $f$ maps onto a convex domain is given by

$$
R=\frac{1}{2}\left[(k+2)-\sqrt{\left(k^{2}+4 k\right)}\right] .
$$

The function $F_{k}$ defined by (2.1) shows that this result is best possible. In particular, when $k=2, R=2-\sqrt{3}$, which is well known. This result also follows from the remark in $[3, \mathrm{p} .23]$.

PROOF: By definition

$$
z f^{\prime}(z)=\operatorname{ag}^{\prime}(z) h(z) \quad g \varepsilon V_{k} ; \operatorname{Re} h(z)>0 .
$$

Thus

$$
\frac{\left(z f^{\prime}(z)\right)^{\prime}}{f^{\prime}(z)}=\frac{\left(z g^{\prime}(z)\right)^{\prime}}{g^{\prime}(z)}+\frac{z h^{\prime}(z)}{h(z)}
$$

and so

$$
\operatorname{Re} \frac{\left(z f^{\prime}(z)\right)^{\prime}}{f^{\prime}(z)} \geq \operatorname{Re} \frac{\left(z g^{\prime}(z)\right)^{\prime}}{g^{\prime}(z)}-\left|\frac{z h^{\prime}(z)}{h(z)}\right|
$$

For $g \varepsilon V_{k}$, it is well known [9] that, for $z=r e^{i \theta}, 0 \leq r \leq 1$,

$$
\operatorname{Re} \frac{\left(z g^{\prime}(z)\right)^{\prime}}{g^{\prime}(z)} \geq \frac{r^{2}-k r+1}{1-r^{2}}
$$

Hence

$$
\operatorname{Re} \frac{\left(z f^{\prime}(z)\right)^{\prime}}{f^{\prime}(z)} \geq \frac{r^{2}-k r+1}{1-r^{2}}-\frac{2 r}{1-r^{2}}=\frac{r^{2}-(k+2) r+1}{1-r^{2}}
$$

This gives the required result.

REMARKS 3.

(i). We also note that the extremal function $F_{k}(z)$ defined by (2.1) is the same function as $F_{\beta}(z)$ defined by equation (2.6) in [3]. As A. W. Goodman has pointed out that this function is sometime referred to as the generalized Koebe function. 
(ii). We conjecture that the class $T_{k}$ is a proper subclass of the class $K(\beta)$ as defined in [3], since in the definition of $T_{k}, g \varepsilon V_{k}$ and we know that $g \varepsilon V_{k}, 2 \leq k \leq 4$, is convex in one direction and all the functions in one direction form a proper subclass of the class of close-to-convex functions.

(iii). It remains open whether $T_{k}$ is a linear in variant family.

ACKNOWLEDGEMENT. The author wishes to thank Prof. A. W. Goodman and the referee for their interesting and helpful comments, which influenced the final version of this paper.

\section{REFERENCES}

1. HAYMAN, W. K. Multivalent Functions, Cambridge University press, 1967.

2. KAPLAN, W. Close-to-convex Schilcht Functions, Mich. Math. J. I (1952), $169-185$.

3. GOODMAN, A. W. On Close-to-convex Functions of Higher Order, Univ. Sci. Budapest. Eótvos. Sect. Mathematica, 15 (1972), 17-30.

4. BRANNAN, D. A. On Functions of Bounded Boundary Rotation, Proc. Edin. Math. Soc. $\underline{2}(1968 / 69), 330-347$.

5. PAATERO, V. Uber Gebiete von beschrankter Randdrehung Annal/Acad. Sci. Fenn. Ser A 37 (1933), 20pp.

6. GolUSIN, G. M. Geometrische Functionstheorie, Berlin, 1957.

7. POMMERENKE, Ch. On Starlike and Close-to-convex Functions, Proc. Lond. Math. Soc. $\underline{3}(1963), 290-304$. 


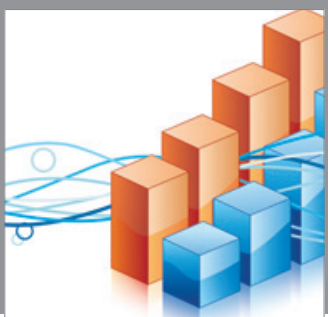

Advances in

Operations Research

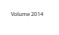

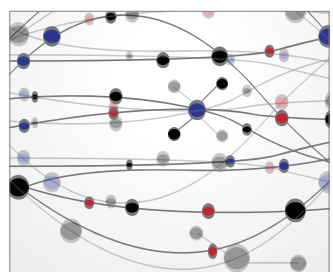

\section{The Scientific} World Journal
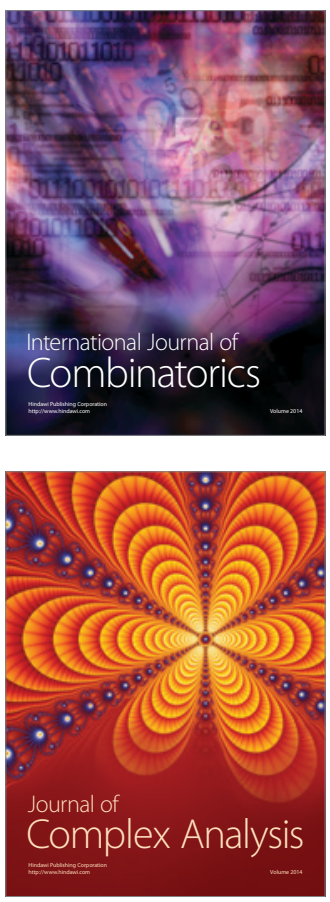

International Journal of

Mathematics and

Mathematical

Sciences
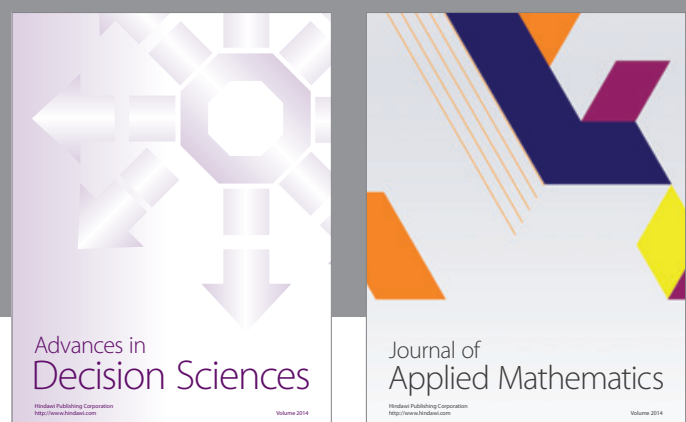

Journal of

Applied Mathematics
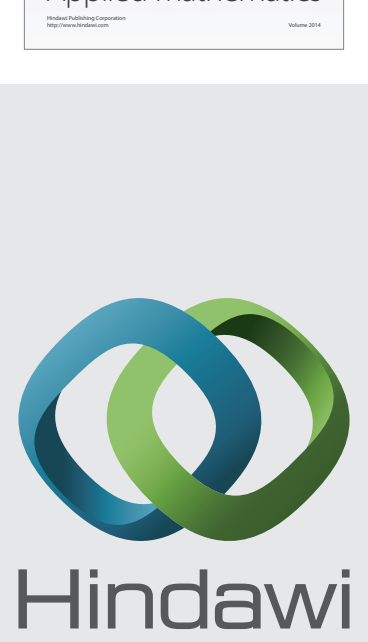

Submit your manuscripts at http://www.hindawi.com
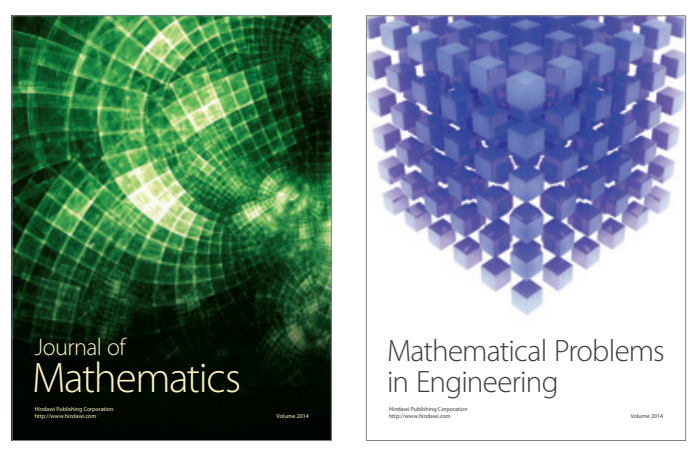

Mathematical Problems in Engineering
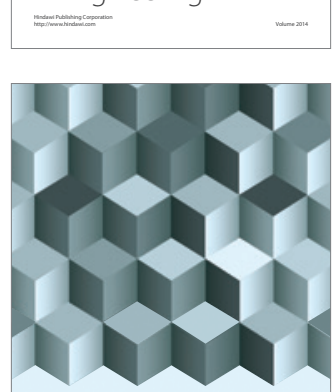

Journal of

Function Spaces
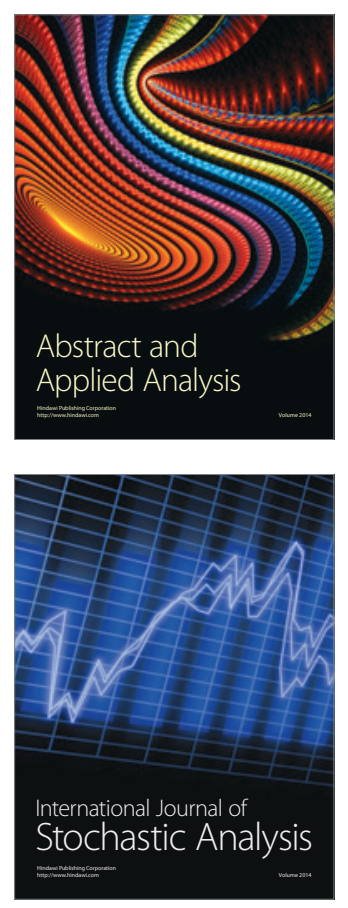

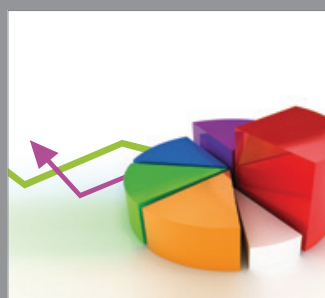

ournal of

Probability and Statistics

Promensencen
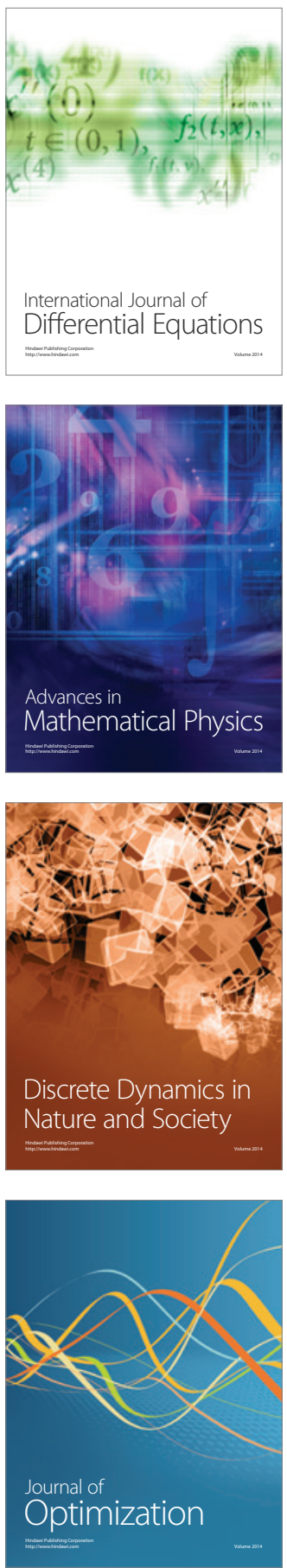